\title{
A Brief Analysis on the Influence of New Media on Communication Sciences Studies at China Mainland Region
}

\author{
Nisi $\mathrm{Yu}^{1, \mathrm{a}}$ \\ ${ }^{1}$ Department of News and Communication, Communication University of China, Beijing 100000, \\ China \\ ayunisi@126.com
}

Keywords: new media; mainland region; communication sciences; research; influence.

Abstract. At present, China has gradually entered the era of new media. With the extensive application of computer and internet technology, people can easily search and access to information. It provides a channel for ordinary people, and even the vulnerable groups to publish their viewpoints. As being affected by the new media, studies on communication sciences present both positive and negative results. Although there are more and more research data available for scholars to search from, a trend of academic fraud has been formed unconsciously. The paper will perform brief analysis focusing on the influence of new media on communication sciences studies at China mainland region.

\section{Introduction}

At studies on communication sciences, journal papers on communication sciences have always been the major approach and channel for communication sciences study. The research and development direction on communication sciences can be detected from the quality level of such papers in the future. At the era of new media, the exchange and communication among specialists and scholars in communication academic field can be more and more convenient. The academic vision can be enlarged. The paper can introduce the concept of new media and communication studies through brief analysis to describe the influence of new media on communication sciences at China mainland region.

\section{Brief introduction of new media}

New media, just as its name implies, refers to the latest media forms at present social. It is a media format diametrically opposite to traditional media forms and communication tools such as newspapers, radio, magazines, television and books. The newly emerged modern media and communication tools at present mainly include internet, electronic communication equipment and satellite communications facilities etc.. New media has tremendous preponderance of illustration, real time transmission and strong interactivity. It can mobilize all the senses at the process of information accepting and perception. As the new media being developed and utilized, the user group can enjoy convenient media services with superior quality which has significantly optimized communicating effects and enlarged the coverage area of communication. Although there is no clear definition and concept on the new media from all sectors of society at current stage, with the development of modern information technology, social people from all walks of life have been paying more and more attentions on new media. The application scope has become increasingly wider [1].

\section{Brief introduction of communication sciences}

(I) Basic conception

Communication sciences can be traced back to 1930s. It is initially put forward by Wilbur Schramm, a famous expert and scholar in the United States. Therefore, Schramm is known affectionately as "the father of communication sciences" and the "earliest founder of communication sciences". Schramm established the first institution in the world to study the communication sciences, 
and compiled the first textbook for communication sciences. The so called communication sciences refers to a specific discipline studying the relationship among human behaviors and the occurrence, development propagation rule, people and society transmission as the research core contents. It is a science to study the social information system and operation rules as well. Simply speaking, communication sciences is a discipline for people to study how to complete social information exchange by using the symbols. The applied discipline is extremely extensive, including anthropology, sociology and political science etc.. Communication sciences is also known as communication for short [2].

(II) Research emphasis

Communication sciences is mainly applied to study human communicational behaviors as well as the communication rule during the occurrence and development process, as well as the specific relationship between human society and communication sciences. During communication sciences studying process, communication mainly refers to communication transmitter, communication sciences media, communication contents and communication effects etc.. The research priorities of communication sciences cover information transmission among human being, communication means or communications media adopted, specific speed and communication purposes, communication control and eventual communication effects.

(III) Research scope

The main research scope of communication sciences includes introversion, interpersonal, public, mass, organizational communication. Among them, mass communication is the major research scope.

\section{Influence of new media on communication sciences studies at studies at China mainland region}

(I) Paper writing specification

Communication sciences paper writing requirements in international have been clearly stipulated at present. The communication sciences paper prepared in standard specific standard shall contain five necessary elements, respectively as foreword, research method, results overview, summary and literature review. Specific requirements are available for the five necessary elements. For example, it is necessary to indicate the research method, reliability of such research method, specific process and details of the method executed. Scoring system evaluation is taken at each part of the paper from 1 to 4. The standard paper shall at least manifest more than three key points. The score up to standard is 4 . As being affected by new media, there are about 2000 academic paper on communication sciences research published at China mainland region. In addition, it presents a rising trend year by year which indicates that due to the high new media speed, wide scope and tremendous preponderance. There are more and more people engaged in studies. The research degree is more and more deep, and increasingly professional. From Table 1 we can see that the quantity of paper of communication sciences presents rising trend since from the word of new media being officially put forward by our country. On the aspect of research method being adopted, the rate of content analysis has been gradually increasing, and has gradually become the major research method of communication sciences [3]. In addition, as being affected by the new media, the rate reaching the standard of paper on communication sciences at China mainland region presents a qualitative leap. The zero success rate in 1999 increased to $60 \%$ in the last year.

Table 1 The proportion of paper on communication sciences studies and content analysis method under new media

\begin{tabular}{|c|c|c|c|}
\hline \multirow[t]{2}{*}{ Time } & \multirow{2}{*}{$\begin{array}{l}\text { Paper } \\
\text { amount }\end{array}$} & Proportion & Proportion \\
\hline & & $\begin{array}{l}\text { of } \\
\text { media \% }\end{array}$ & $\begin{array}{l}\text { of content } \\
\text { analysis }\end{array}$ \\
\hline 2007-2010 & 511 & 29.0 & 30.7 \\
\hline 2010-2013 & 756 & 46.6 & 52.3 \\
\hline 2013-2016 & 903 & 55.9 & 73.7 \\
\hline
\end{tabular}


(II) Adopting speculative method

China has a long traditional history. Scholars commenting on politics in China have been existing since from ancient times with over thousand years history. The fundamental difference between the communication sciences at China mainland region and that in western countries. The western communication is derived from sociology. While the communication sciences at China mainland region directly inherits journalism. Therefore, paper writing generally adopts speculative method. Namely perform inference proof logically. Subjective idea is adopted to complete evidence collection. Basically, do not perform assumption nor set falsification. Therefore, while comparing with communication sciences research paper of western professional specifications, the papers on communication sciences are more random lacking of scientific and preciseness. As being affected by new media, the person engaged in communication sciences at China mainland region gradually learn the advanced communication sciences research results in western countries actively via internet. It actively gets close to western countries on standards and specification. Consequently, it has acquired significant progress on paper writing specification. The research method adopted is more scientific and reasonable. The opportunity of adopting speculative method has been gradually decreasing [4].

Table 2 Proportion of research paper speculative method of communication sciences at China mainland region under the influence of new media.

\begin{tabular}{ccc}
\hline Time & $\begin{array}{c}\text { Paper } \\
\text { amount }\end{array}$ & $\begin{array}{c}\text { Ratio } \\
\text { using } \\
\text { speculative } \\
\text { paper \% }\end{array}$ \\
\hline 2010 & 40 & 58.8 \\
2011 & 36 & 52.4 \\
2012 & 29 & 44.0 \\
2013 & 28 & 33.3 \\
2014 & 25 & 28.6 \\
2015 & 20 & 15.4 \\
\hline
\end{tabular}

\section{(III) References}

At research paper writing process of communication sciences, the two indicators are used to measure the references to list the specific quantitative and literature origins including the ratio of Chinese references and foreign references. As being affected by new media, people all over the world can communicate and exchange anytime and anywhere. People IS no longer subject to the limitation of time and space. Not only that, people can view communication research academic exchange discussion around the world through virtual cross-border exchanges. With the help of internet, people can learn the professional scholars in western developed countries at the practice of references and standards; they can review the document literature on communication sciences in the library of famous universities in the world. In view of language communication obstacles, the rate of reading skillfully foreign reference to 2005 presents a rising tendency gradually. In 2005, there are 36 papers on communication sciences in total at China mainland region. The proportion of 21 paper referenced is $16.7 \%$. About $20 \%$ paper literature is in Chinese; there are 35 papers on communication sciences research in total. There are 21 papers referenced accounting for $15.7 \%$. Only $11.4 \%$ reference literature are in Chinese. Thus it can be seen that communication sciences researches at Mainland China are close to the international standard under the influence of new media.

Conclusion: In a word, by utilizing the modern electronic information technology and internet technology, new media can realize virtual cross-border communication. Communication sciences are not restricted to Mainland China but also get close to internationalization. More and more mainland communication researchers can participate in international academic communication. With the help of new media, the gap between communication sciences research and the international advanced communication sciences has been gradually minimized. Through the simple analysis on communication sciences paper writing standard, speculative method adaption and references status, it 
can be seen that the communication sciences researches have been gradually changing at China mainland under the influence of new media.

\section{References}

[1] YIN Yuqian A Brief Analysis on the Influence of New Media on Communication Sciences Studies at Greater China Region Especially China Mainland Region [A]. World Media Industry Review (Edit 2) [C]:, 2015:39

[2] RAO Dejiang, MO Meifeng, XIONG Lei, WANG Xiao, LIU Yinglei Review on the Influence of New Media on communication sciences at mainland region [J]. Media Development Research Report in China, 2015, 00:66-157

[3] TAO Shaojing Research on communication sciences development at mainland region under the environment of new media, 2014

[4] QI Tao, XUE Qiaozhen, ZHAO Yonghua, CHEN Jianping, MA Yifei, SUN Fei, JIN Shi, REN Min, ZHANG Yunyan, XIANG Chunxiao. Influence on communication sciences development at mainland region under the environment of new media [A]. Journalism Analects (edit 21)--The 38th anniversary special for memory of the reform and opening-up [C], 2016:77. 